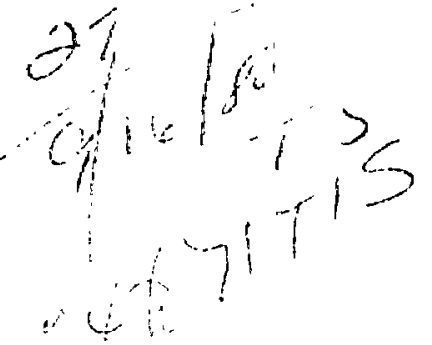

\title{
INFORMAL WORKSHOP ON INTENSE POLARIZED ION SOURCES: \\ A Summary
}

\author{
O'Hare Hilton Hotel \\ O'Hare International Airport \\ Chicago, Illinois \\ March 6, 1980
}

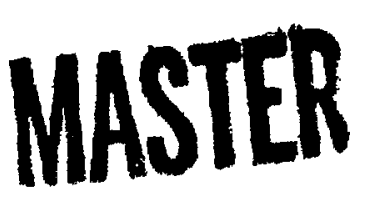


Distribution Categories:

Physics-Atomic and Molecular (UC-34a)

Physics-Particles and Fields (UC-34d)

ANL $-80-73$

ARGONNE NATIONAL LABORATORY

9700 South Cass Avenue

Argonne, Illinois 60439

INFORMAL WORKSHOP ON INTENSE POLARIZED ION SOURCES:

A Summary

O'Hare Hilton Hotel

o'Hare Internationa1 Airport Chicago, Ilinois

March 6, 1980

\author{
Organized and Edited by: \\ Peter F. Schultz \\ Accelerator Research Facilities Division
}

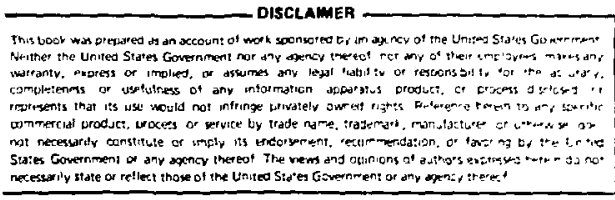

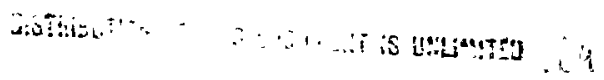




\section{PREFACE}

The Accelerator Research Facilities Division of Argonne National Laboratory sponsored an Informal Workshop on Intense Polarized Ion Sources on March 6, 1980. For the convenience of those attending, the Workshop was held at the 0'Hare Hilton Hotel at O'Hare International Airport, Chicago, Illinois. Eighteen people from twelve institutions attended.

The main topic was the concept of utilizing optically-pumped alkali vapor described by L. W. Anderson of the University of Wisconsin [Nuc1. Instrum. Methods 167,369 (1979)] and the questions he raised in that paper. The workshop started with a talk by Professor Anderson in which he further described the concepts of his paper and suggested some topics which he felt needed further investigation. The discussion following Professor Anderson's talk centered on the questions he had raised and the possible means of investigating them. Later on in the day, the discussion switched to other possible high-intensity polarized sources, in particular the H/Cs charge exchange source similar to the system operating at the University of Wisconsin.

The following pages are a summary of Professor Anderson's talk and the discussions following it. I am grateful to D. G. Crabb and R. C. Fernow for providing the notes on which this report is based.

P. F. Schultz

Argonne National Laboratory 


\section{ABSTRACT}

OPTICALLY-PUMPED ION SOURCE by L. W. Anderson

Optical Pumping of Target.

Beam Intensity.

The Magnetic Field Problem.

Comparison to Other Ion Sources and Summary . 


\title{
INFORMAL WORKSHOP OI INTENSE POLARIZED ION SOURCES: A SUMMARY \\ by
}

\author{
Peter F. Schultz
}

\section{ABSTRACT}

An Informal Workshop on Intense Polar1zed Ion Sources was held on March 6, 1980, at the O'Hare Hilton Hotel, Chicago, Illinois. The purpose of the Workshop was to discuss problems in developing higher-intensity polarized proton sources, particularly the opticalily-pumped source recently proposed by $\mathrm{L}$. W. Anderson of the University of Wisconsin. A summary of the discussions is reported. 


\section{OPIICALLY-PUMPED ION SOURCE*}

\section{W. Anderson}

The proposed source of polarized $\mathrm{H}^{-}$Ions (FIg. 1) uses a $1 \mathrm{~W}$ dye laser to polarize a Na vapor target by optically pumping the Na atoms in a magnetic fleld. The reason for interest in an optically-pumped polarized ion source can be understood from the following simple calculations. A $1 \mathrm{~W}$ dye laser has a photon flux of $3 \times 10^{18}$ photon/sec. Calculations indicate that it will take 1.5 photons to polarize a $\mathrm{Na}$ atom in the magnetic field if the field strength $B \gg B_{c}$. Thus, for $50 \%$ absorption, one can polarize about $10^{18} \mathrm{Na}$ atoms per second.

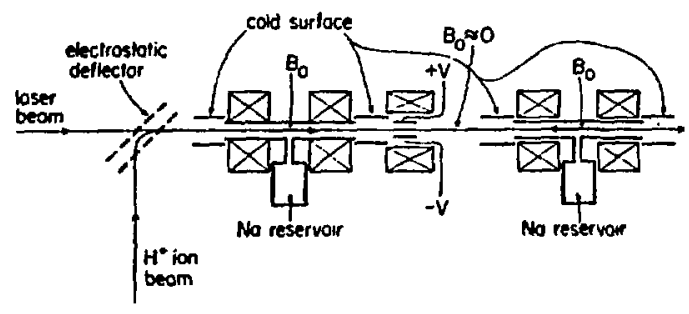

Fig. 1. Schematic Diagram of Proposed Optically-Pumped Polarized Ion Source
If the $\mathrm{Na}$ vapor target $1 \mathrm{~s} 1 \mathrm{~cm}$ in diameter, then the average time between wall collisions is about $10^{-5} \mathrm{sec}$ for a $600^{\circ} \mathrm{K}$ temperature. Thus, one can produce a target with about $\pi=10^{13} \mathrm{Na}$ atoms $/ \mathrm{cm}^{2}$, even if every wall collision depolarizes the $\mathrm{Na}$ atoms. Loss by effusion from the target ends is smail compared to wall loss of polarization.

The total cross-section, $\sigma_{+o}$, for the charge transfer reaction

$$
\mathrm{H}^{+}+\mathrm{Na}+\mathrm{H}^{\mathrm{O}}+\mathrm{Na}^{+}
$$

at $5 \mathrm{keV}$ energy is $6 \times 10^{-15} \mathrm{~cm}^{2}$. Thus, $6 \%$ of the $\mathrm{H}^{+}$emerges neutral from the first target (for $\pi=10^{13}$ atoms $/ \mathrm{cm}^{2}$ ). The equilibrium fraction of $\mathrm{H}^{-}$ions $F^{\infty}=(7.3 \pm 0.7) \%$ in the second target. Thus, one can get $4 \mu \mathrm{A} \mathrm{H} \mathrm{H}^{-}$per $\mu \mathrm{A}$ $\mathrm{H}^{+}$incident on the first target.

The possible polarization of the $\mathrm{H}^{-}$depends on the level the $\mathrm{H}^{\circ}$ is produced in. The energy defect is smaller for $n=2$ than for $n=1$ or higher $n$ 's. Production will be in $n=2$ predominantly. Radiation from the $n=2$ to $n=1$ transition will carry away angular momentum, and the polarization of the ground level will be less than the Na atom polarization. If $100 \%$ polarized

*This text is based largely on the viewgraphs presented by Proffesor Anderson and on notes taken by D.G. Crabb, R.C. Fernow, and P.F. Schultz and is not intended to be the equivaient of a scientific journal publication. 
electrons from $\mathrm{Na}$ are captured in the $2 \mathrm{p}$ level, then after radiative decay $P_{e}=11 / 27=41 \%$ in the ground 15 level of $H^{\circ}$. Capture into $2 \mathrm{~S}$ or $n=3$ levels also leads to loss of polarization.

The actual level populations are not known from either experiment or theory. Therefore, experiments are needed to determine these populations.

The loss of polarization can be avoided if $\overrightarrow{\mathrm{L}}$ and $\overrightarrow{\mathrm{S}}$ are decoupled by a strong $B$ field. A measure of the coupling of $\vec{L}$ and $\vec{S}$ is the splitting of the $2^{2} \mathrm{P}_{3 / 2}, 2^{2} \mathrm{P}_{1 / 2}$ level in hydrogen.

$$
\left[E\left(2^{2} P_{3 / 2}\right)-E\left(2^{2} P_{1 / 2}\right)\right] / 2 \mu_{0}=3500 \mathrm{G}
$$

Thus, fields as large as $10^{4} \mathrm{G}$ may be needed. Experiments are needed to measure polarization of the $\mathrm{H}^{-}$ions as a function of $B$.

Witteveen measured a nuclear polarization $P=14 \pm 4 \%$ when $\approx 40 \%$ was expected. Witteveen assigued the difference to background gas, but it may be due to loss of polarization from radiation as $\mathrm{H}^{\circ}$ atoms decay to the $\mathrm{n}=1$ level.

The Sona transition between the two targets should present no problems. In fact, it should be easier here than in the Lamb shift sources, since the velocity is $u 3$ times higher.

OPTICAL PUMPING OF TARGET

The Na energy levels for $B \gg B_{c}$ are shown in Fig. 2 .

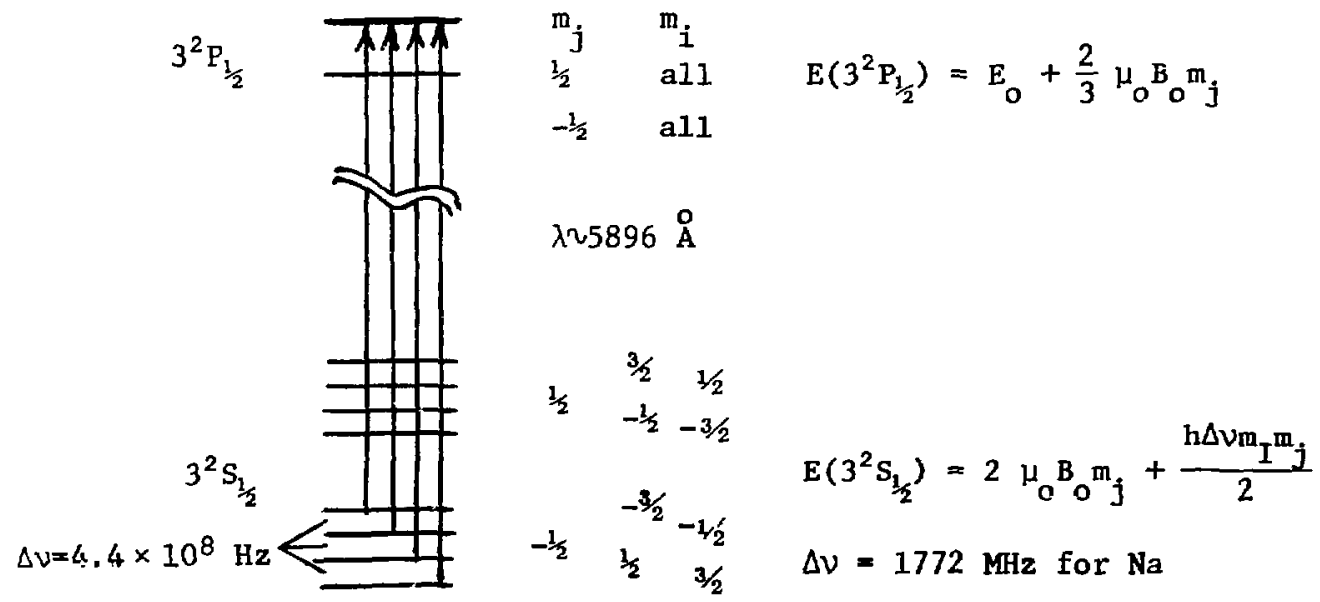

Fig. 2. Optical Fumping Transitions for Left Circularly Polarized Iight 
The spread in frequency for any one line due to Doppler broadening is $\Delta v_{\mathrm{D}}=1.7 \times 10^{9} \mathrm{~Hz}$ at $600^{\circ} \mathrm{K}$.

Each IIne is broadened by $\Delta \nu_{D}$ (Fig. 3a). Thus, the total absorption looks I1ke Fig. 3b.

a)

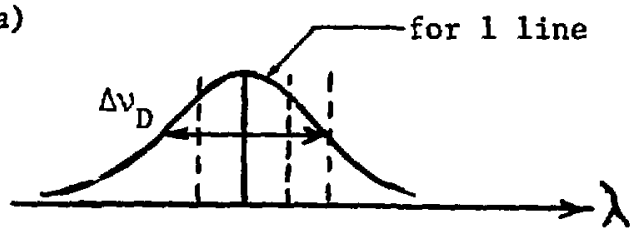

b)

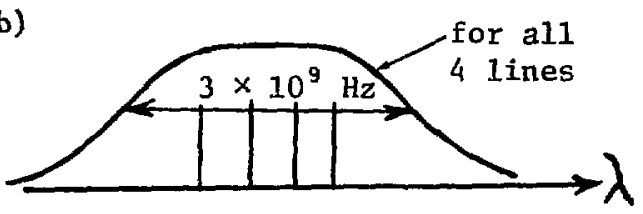

Fig. 3. Doppler Broadening

The laser must not be too narrow or some Doppler-shifted atoms w111 not be pumped. The laser should be about $2 \Delta v_{\mathrm{D}}+\frac{3}{4} \Delta v_{\mathrm{HFS}} \approx 5 \times 10^{9} \mathrm{~Hz}$ in bandwidth.

The relative populations of the ground state sublevels are calculated similar to the method of Franzen and Emslie. The relative transition probabilities are shown in Fig. $4 a$ for the $3^{2} S_{1 / 2}-3^{2} P_{1 / 2}$ transitions. Figure $4 \mathrm{~b}$ shows the transitions which are relevant to optically pumping the Na target.

a)

b)
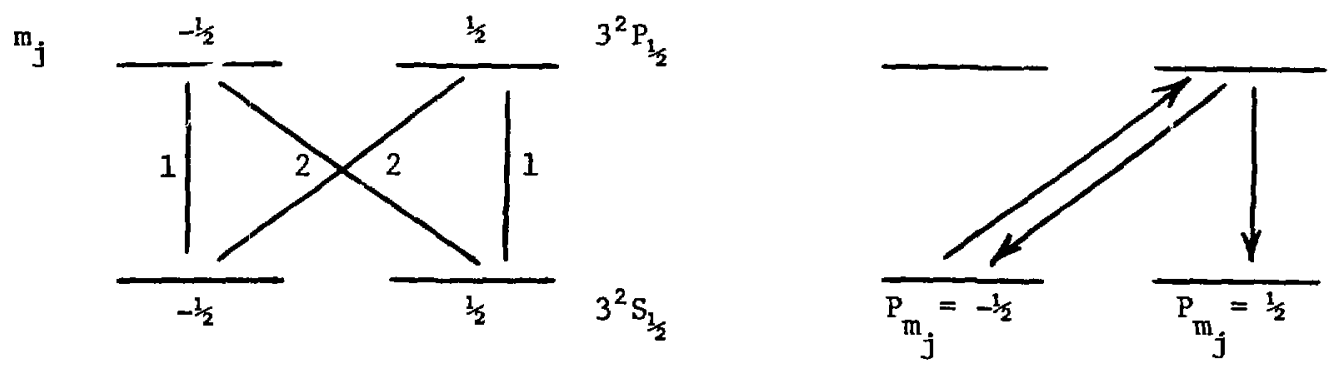

Fig. 4.

The relative populations are given by:

$\frac{\mathrm{dP}_{m_{j}=-1 / 2}}{d t}=\beta_{0} P_{m_{j}=-1 / 2}+\frac{2}{3} \beta_{0} P_{m_{j}=1 / 2}-\left(\frac{P_{m_{j}=-1 / 2}-1 / 2}{\tau}\right)$

$\frac{d P_{m_{j}=1 / 2}}{d t}=\frac{1}{3} B_{o} P_{m_{j}=-1 / 2}-\left(\frac{P_{m_{j}=1 / 2^{-1 / 2}}}{\tau}\right)$ 
where $B_{0}=\int I_{v} \sigma_{v} d v$ and $\tau=$ relaxation time. The solution to the differential equations is:

$$
P_{m_{j}=-\frac{1}{2}}=\frac{1}{2\left(1+\frac{2}{3} \beta_{0} \tau\right)}
$$

where $\beta_{0}=\int_{0}^{\infty} I_{v} \sigma_{v} d \nu \simeq I_{0} \int_{0}^{\infty} \sigma_{v} d v$

$$
=I_{0} \pi c r_{0} f=4.4 \times 10^{-3} I_{0}
$$

using $f=1 / 6$ for the oscillator strength. If the laser bandwidth is $10^{10} \mathrm{~Hz}$, then $\beta_{0}=1.7 \times 10^{6} \mathrm{sec}^{-1}$. The polarization of the Na target is:

$$
\begin{aligned}
P_{e} & =P_{m_{j}=\frac{1}{2}}-P_{m_{j}=-\frac{1}{2}}=1-\frac{1}{\left(1+\frac{2}{3} \beta_{0} \tau\right)} \\
& =88 \%
\end{aligned}
$$

assuming $\tau=1.25 \times 10^{-5} \mathrm{sec}$.

If $3 / 4$ of the photons are absorbed at the line center, then $\beta_{0}$ decreases to $B_{0}=2.1 \times 10^{5} \mathrm{sec}^{-1}$ at the end of the target and $P_{e}=64 \%$ at the end of the target. Thus, $\overline{\mathrm{P}}_{\mathrm{e}}=75 \%$ and cne can produce a target with $\pi=6 \times 10^{12} \mathrm{atoms} / \mathrm{cm}^{2}$. This corresponds to about $2.2 \mu \mathrm{A}$ of polarized $\mathrm{H}^{-}$ions per $\mathrm{mA}$ of $\mathrm{H}^{+}$incident. Other bandw.' Aths or changes in the $B_{0}$ field can change this number somewhat, but not by a large fraction. More laser power per bandwidth can improve $P_{e}$ and $\pi$ significantly. Experiments should be done that test $P_{e}$ and $\pi$ for an opticallypumped target.

What is $\tau$ ? Does $\mathrm{Na}$ depolarize at each wall collision? Can polyethylene or some other material prevent depolarization? A wall surface that permits bouncing without depolarization can lengthen $\tau$ and increase the value of $P_{e}$ and $\pi$ that can be obtained by a substantial fraction. Experiments are needed on wall properties of $\tau$.

The target length $\pi$ cannot become very large, as imprisonment of resonance radiation will limit it, probably by about $\pi=5 \times 10^{13} \mathrm{atom} / \mathrm{cm}^{2}$.

The mechanism for imprisonment of radiation is shown in Fig. 6 . 


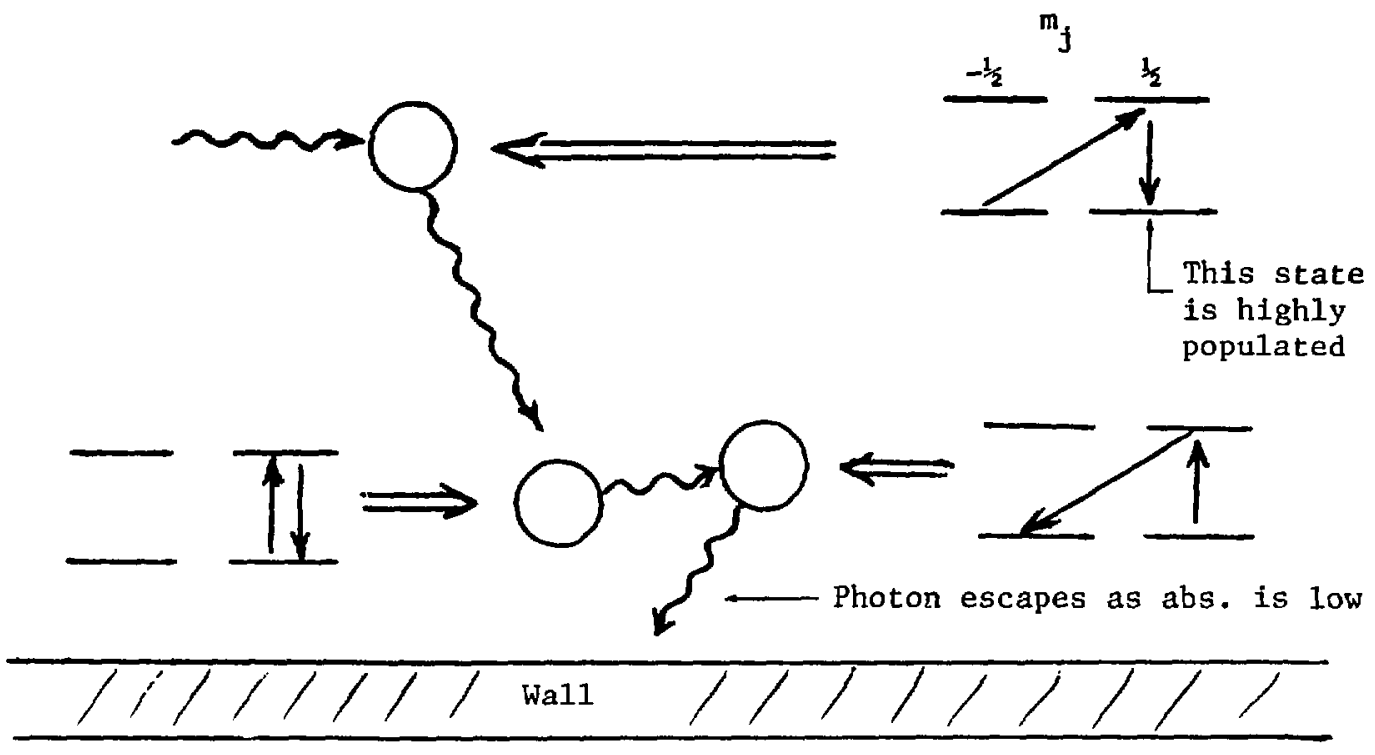

Fig. 6

Imprisonment of radiation limits the density at the center of the target to a density from which radiation can have a reasonable chance of escape without absorption for $\ell=1 / 2 \mathrm{~cm}$ (the radius of the target). Experiments are needed to determine the exact density at which imprisonment limits $\pi$.

\section{BEAM INTENSITY}

In my paper, I assumed $10 \mathrm{~mA}$ of $\mathrm{H}^{+}$beam. With this beam, an output polarized $\mathrm{H}^{-}$beam of about $22 \mathrm{HA}$ is possible with a nuclear polarization of about $78 \%$. But can one really put $10 \mathrm{~mA}$ of $\mathrm{H}^{+}$through a tube $20 \mathrm{~cm}$ long? The space charge limit for the current is:

$$
\begin{aligned}
I & =38 \times 10^{-6}\left(\frac{d}{l}\right)^{2} v^{3 / 2} \frac{1}{m^{1 / 2}} A \\
& =0.8 \mathrm{~mA}
\end{aligned}
$$

Space charge neutralization will occur, of course, so the question is how much current can be put through a tube? Experiments are needed. 


\section{THE MAGNETIC FIELD PROBLEM}

The fringe field of the solenoid (Fig. 7) will impart transverse velocity to the beam. The radial field is given by:

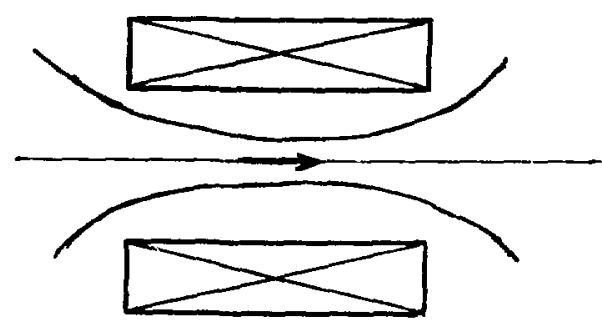

$B_{0}=B_{z}$ at center of solenoid

Fig. 7

$$
\begin{aligned}
& \int 2 \pi r B_{r} d l=\pi r^{2} B_{o} \\
& \int B_{r} d l=\frac{r}{2} B_{o}
\end{aligned}
$$

The transverse force is:

$F_{t}=e_{z} B_{I}$

so,

$$
\begin{aligned}
m v_{z} & =\int F_{t} d t=\int e v_{z} B \frac{d l}{v_{z}} \\
& =\int e{ }_{r} d l=\frac{e B_{o} r}{2}
\end{aligned}
$$

So, $\frac{v_{t}}{v_{z}}=\frac{e B_{o} r}{2 m v_{z}}=0.25$ if $B_{o}=10^{4}$ Gauss, $r=.5 \times 10^{-2} \mathrm{~m}, m=$ mass of proton, and $v_{z}=10^{6} \mathrm{~m} / \mathrm{sec}(5 \mathrm{keV}) ; v_{t} / v_{z}$ of 0.25 is clearly unacceptable. Thus, $B_{0}$ must be lower or the ion source must operate in the same $B_{0}$. Experiments are needed to show whether either of these is possible.

COMPARISON TO OTHER ION SOURCES AND SUMMARY

The colliding beam $\left(\mathrm{H}^{\circ}+\mathrm{Cs}^{\circ}\right)$ polarized ion source at the University of Wisconsin has produced $3 \mu \mathrm{A}$ of $\mathrm{H}^{-}$with polarization near 1 . The ion source runs well at $1 \mu \mathrm{A}$ output, but there remain some problems of sparking, etc. A11 remaining problems seem soluble without great difficulty. With study, colliding beams (either $\mathrm{H}^{\circ}+\mathrm{Cs}^{\circ}$ or $\mathrm{H}^{\circ}+\mathrm{H}^{-}$) can no doubt be increased in intensity. The $\mathrm{Cs}^{+}$scurce, especially, should be worked on as the $\mathrm{H}^{-}$beam is directly proportional to the $\mathrm{Cs}^{\circ}$ beam.

1. At the present time, the $\mathrm{Cs}^{\circ}+\mathrm{H}^{\circ}$ colliding beam source is the most promising polarized ion source.

2. The $\mathrm{H}^{-}+\mathrm{H}^{\circ}$ colliding beam ion source is also promising and should be pursued.

3. The optical-pumping ion source should be researched so that the questions raised in this talk are answered. Only then can a realistic assessment of the optical-puming 
ton source be given. The optical-pumping ion source may eventually be a good source.

4. For $\mathrm{D}^{-}$ions, the optical-pumping source has no means for rf transitions, whereas the colliding beam sources do.

5. The optical-pumping source may be useful for $T$ keams, whereas the colliding beam sources cannot be.

6. The colliding beam source can be rum in near zero $B$ fleld, whereas optical-pumping sources cannot, so emittance may be better for colliding beam sources. 


\title{
DISCUSSION
}

The discussion following Professor Anderson's talk covered many of the questions he had raised. The discussion is summarized in the following paragraphs.

\section{ATOMIC PHYSICS}

Los Alamos plans to investigate the relaxation time $\tau_{R}$ using a laser and a Na cell they have obtaired. The method they propose to use is to irradiate the $\mathrm{Na}$ cell, located in a $\mathrm{B}=3500 \mathrm{G}$ field, with circularly polarized light and measure the transmitted intensity vs. the incident intensity (Fig. 8).

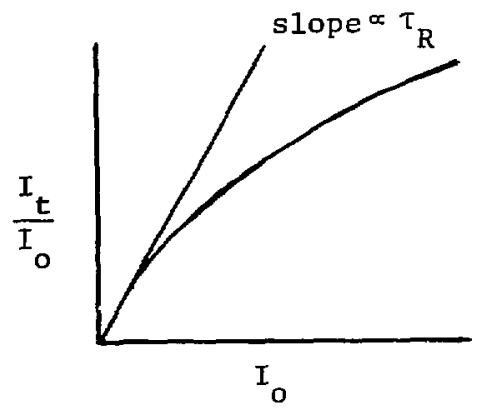

Fig. 8

\begin{abstract}
As the laser intensity, $I_{0}$, is increased, the polarization of the target also increases, decreasing the number of atoms in the photon absorbing state. When the target is completely polarized, the transmission will be $100 \%$. The initial slope of the curve depends on the relaxation time $\tau_{\mathrm{R}}$.
\end{abstract}

Their investigation will include studies of wall coaiings and the cell design in order to optimize $\tau_{R}$. The polarization of the Na target can be measured, using the Faraday effect.

Lasers with the required intensity and bandwidth are commercially avallab.te, so the discussion concerning them centered more on what specific requirements would be desired. In order to avoid inequalities in polarizations arising from polarization reversal, the bandwidth would have to completely overlap both $\mathrm{m}_{j}=1 / 2$ and $\mathrm{m}_{j}=-1 / 2$ sets of transitions. Otherwise the laser frequency would have to change at the same time the polarization is reversed. In either case, the polarization can be easily reversed with a Pockels cell. The recommendation was made that lasers with higher power than actually needed be purchased, since the dye laser tube lifetime would be greatly increased. For instance, a 2 - to $3 \mathrm{~W}$ laser shculd be purchased if $1 \mathrm{~W}$ of power is needed. 
If nondepolarlzing wall coatings can be used for the Na target in the environments envisioned, the laser power required would be less. It is known that some polymers such as polyethylene do not cause depolarization, so experiments should be done to invistigate their survivability. The diameter of the $\mathrm{Na}$ target cell is not crucial, as long as the optically-pumped region completely overlaps the proton beam reglon. Therefore, the design of the target can be concerned mainly with physical and thermal properties. The density of $\mathrm{Na}$ in the target will be limited by radiation imprisonment and birefringence. The latter is expected to become important at densities of $\pi \gtrsim 10^{14} \mathrm{~cm}^{-2}$ which is above the densities currently anticipated.

\section{BEAM OPTICS}

The primary topic associated with beam optics concerned the effect of the $10 \mathrm{~kg}$ solenoidal field on the divergence of the $\mathrm{H}^{\circ}$ beam. A suggested alternative configuration shown in Fig. 9 places the $\mathrm{H}^{+}$source in the same solenoldal field as the Na target.

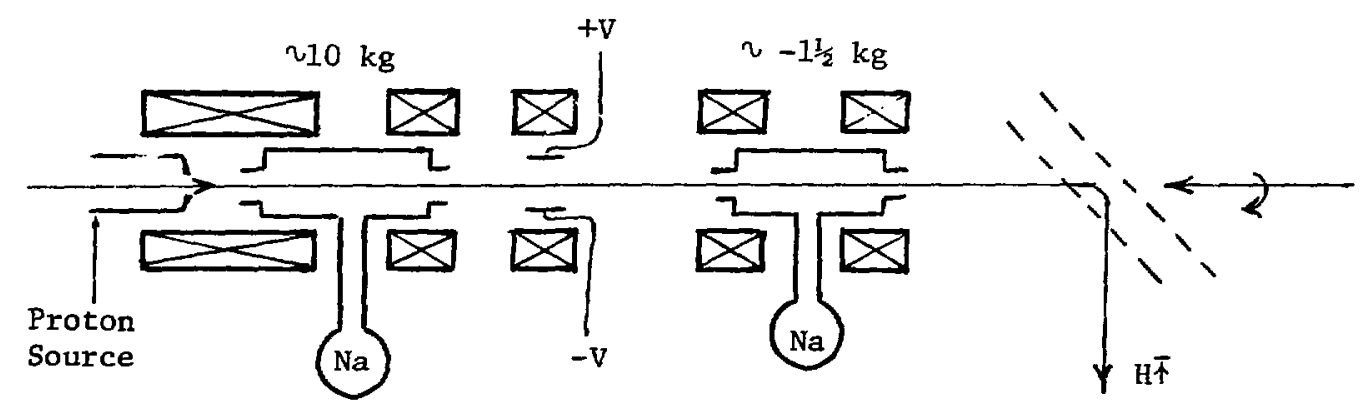

Fig. 9. Alternative Configuration for Optically-Pumed Polarlzed Ion Source 
Some types of proton sources have $\nu_{3} \mathrm{~kg}$ fleld and probably one could operate at $410 \mathrm{~kg}$. To eliminate unpolarized background due to unwanted spectes (like $\mathrm{H}_{2}^{+}$), some magnetic analysis would have to be done on the $\mathrm{H}^{\bar{f}}$ beam. The laser beam would have to be incident antiparallel to the $\mathrm{H}^{+}$bean direction. In this conflguration, it might be necessary to use a different vapor than $\mathrm{Na}$ for ionization from $\mathrm{H}^{\circ}$ to $\mathrm{H} \bar{F}$. Another possible configuration that was suggested would be to simulate the type of injection into a cyclotron, but in the reverse direction (Fig. 10).

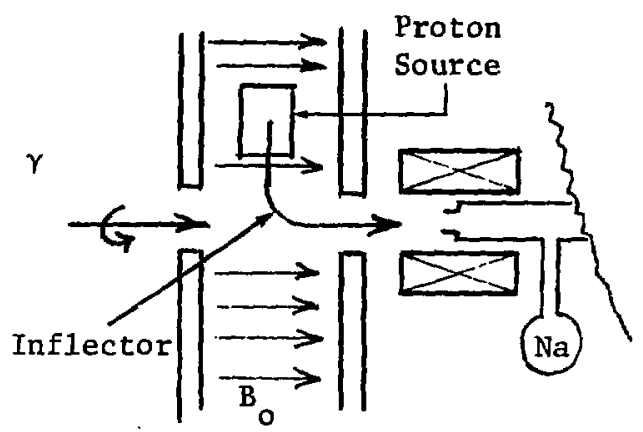

Fig. 10

DISCUSSION OF CHARGE EXCHANGE SOURCES

(COLLIDING BEAM SOURCES)

Wisconsin told of their experience with their $\mathrm{H}^{\mathrm{O}}+\mathrm{Cs}^{\circ} \rightarrow \mathrm{H}^{-}+\mathrm{Cs}^{+}$ source. The Cs beam has several $\mathrm{mA}$ intensity. However, at $240 \mathrm{kV}$, it is a good sputter beam and causes some surface erosion. The surface iontzation tungsten source has a lifetime of 150 hours before its performance becomes degraded by a factor of 2. To prevent electron backstreaming which erodes the $\mathrm{W}$ button, the extractor is run with a negative potential which overfocuses the $\mathrm{Cs}^{+}$beam, and the overlap of the $\mathrm{Cs}^{\circ}$ and $\mathrm{H}^{\circ}$ beams is not optimized. However, Wisconsin gets about $1 \mathrm{\mu A} \mathrm{H}^{-}$per $\mathrm{mA} \mathrm{Cs}{ }^{+}$.

The intensity of $\mathrm{H}^{-}$in the Cs colliding beam source can most 1ikely be increased. One could, for instance, use a $\mathrm{Cs}^{+}$source different from the surface ionizer - for instance, a Penning source (similar to the one made by Hughes for the ANL $\mathrm{Xe}^{+}$beam for the ion beam fusion program). Also, the experience of ANL shows that cooling the dissociator nozzle of the atonic hydrogen beam source can result in $2^{\frac{1}{2}}$ times the intensity compared to no 
cooling. ANL plans to continue Investigating the effect of cooling. For synchrotron applications, pulsing the dissociator can also increase the intensity by a factor of 2 .

The other reaction suggested by Jaeber11 in 1968,

$$
\mathrm{H}^{\mathrm{P}}+\mathrm{D}^{-}+\mathrm{H} \bar{\mp}+\mathrm{D}^{\mathrm{O}}
$$

should provide high intensity if the problems of space charge of the slow $\mathrm{D}^{-}$ are solved. The cross section is highest for small relative velocfties, but for intense $D^{-}$currents such as are avallable now, $\sim 50$ to $100 \mathrm{~mA}$, space charge forces are formidable. 


\section{CONCLUSIONS}

The biggest question concerning the optically-pimped source involved the large divergences caused by performing charge exchange in a high solenoid field. If this problem could be solved (either by determining that a field much smaller than $10 \mathrm{~kg}$ could be used or by some different configuration), the optically-pumped source would have a good chance of succeeding in producing currents of $100 \mu \mathrm{A}$ or more.

The charge exchange source of the H/Cs type has been shown to work quite well. With refinements, particularly with respect to the cesium beam, this type of source should be able to achieve many times more beam than currently obtained at the University of Wisconsin. 


\section{LIST OF PARTICIPANTS}

\section{$\underline{\text { Name }}$}

L. W. Anderson

J. H. Billen

T. B. Clegg

W. Cornelius

D. G. Crabb

S. E. Darden

T. R. Donoghue

R. C. Fernow

M. G. Mazarakis

D. R. Moffett

M. H. Nayfeh

E. F. Parker

P. A. Ouinn

P. W. Schmor

P. F. Schultz

P. Schwandt

T. Trainor

R. York
Affiliation

\author{
University of Wisconsin \\ University of Wisconsin \\ University of North Carolina \\ Los Alamos Scientific Laboratory \\ University of Michigan \\ University of Notre Dame \\ Ohio State University \\ Brookhaven National Laboratory \\ Argonne National Laboratory \\ Argonne National Laboratory \\ University of Illinois \\ Argonne National Laboratory \\ University of Wisconsin \\ TRIUMF \\ Argonne National Laboratory \\ Indiana University \\ University of Washington \\ Los Alamos Scientific Laboratory
}


Distribution for ANL-80-73

Internal:

E. Colton

M. Derrick

R. Kustom

W. E. Massey
M. Mazarakis

D. R. Moffett

J. R. O'Fallon

E. G. Pewitt
L. Ratner

P. Schultz (59)

ANL Contract File

ANL Librartes

TIS Files (6)

\section{External:}

DOE-TIC (27)

Manager, Chicago Operations and Regional office, USDOE

Chief, Office of Patent Counsel, DOE-CORO

President, Argonne Universities Association

Accelerator Research Facilities Division Review Comittee:

G. H. Miley, University of Illinois, Urbana

D. B. Montgomery, Massachusetts Institute of Technology

H. A. Neal, Indiana University

S. D. Putnam, Physics International Co., San Leandro, Cal.

P. H. Rose, Nova Associates, Inc., Beverly, Mass.

E. M. Rowe, University of Wisconsin, Stoughton

L. C. Teng, Fermi National Accelerator Laboratory

E. G. Adelberger, Iniversity of Washington, Seattle

L. W. Anderson, University of Wisconsin, Madison

J. M. Billen, University of Wisconsin, Madison

T. E. Clegg, University of North Carolina, Chapel Hill

W. Cornelius, Los Alamos Scientific Laboratory

D. G. Crabb, University of Michigan, Ann Arbor

S. E. Darden, University of Notre Dame

T. R. Donaghue, Ohio State University

R. C. Fernow, Brookhaven National Laboratory

W. Haeberli, University of Wisconsin, Madison

R. A. Hardekopf, Los Alamos Scientific Laboratory

V. W. Hughes, Yale University

A. D. Krisch, University of Michigan, Ann Arbor

$Y$. Y. Lee, Brookhaven National Laboratory

M. H. Nayfeh, University of Illinois, Urbana

E. F. Parker, Westingho'se-Hanford Co., Richland, Washington

G. C. Phillips, Rice University

P. A. Quinn, University of Wisconsin, Madison

P. W. Schmor, TRIUMF, Vancouver, British Columbia

K. P. Schuler, SLAC, Stanford

P. Schwandt, Indiana University

K. W. Terwilliger, University of Michigan, Ann Arbor

T. Trainor, University of Washington, Seattle

R. York, Los Alamos Scientific Laboratory 